\title{
A longitudinal study of environmental tobacco smoke exposure in children: Parental self reports versus age dependent biomarkers
} Carme Puig1,2, Oscar Garcia-Algar*1,2, Toni Monleon ${ }^{3}$, Roberta Pacifici ${ }^{4}$, Piergiorgio Zuccaro ${ }^{4}$, Jordi Sunyer ${ }^{5}$, Cecilia Figueroa ${ }^{1,2}$, Simona Pichini ${ }^{4}$ and Oriol Vall 1,2

Address: ${ }^{1}$ Environmental and Pediatric Research Unit (URIE), Pediatric Department, Hospital del Mar, Barcelona, Spain, ${ }^{2}$ Department of Pediatrics, Obstetrics and Gynecology, and Preventive Medicine, Universitat Autònoma de Barcelona, Barcelona, Spain, ${ }^{3}$ Department of Statistics, Universitat de Barcelona, Barcelona, Spain, ${ }^{4}$ Department of Therapeutic Research and Medicines Evaluation, Istituto Superiore di Sanità, Rome, Italy and ${ }^{5}$ Center for Research in Environmental Epidemiology (CREAL), Institut Municipal d'Investigació Mèdica (IMIM), Barcelona, Spain

Email: Carme Puig - carmepuig@yahoo.es; Oscar Garcia-Algar* -90458@imas.imim.es; Toni Monleon - amonleong@wanadoo.es; Roberta Pacifici - roberta.pacifici@iss.it; Piergiorgio Zuccaro - piergiorgio.zuccaro@iss.it; Jordi Sunyer - jsunyer@imim.es; Cecilia Figueroa -94020@imas.imim.es; Simona Pichini - simona.pichini@iss.it; Oriol Vall - ovall@imas.imim.es

* Corresponding author

Published: 6 February 2008

BMC Public Health 2008, 8:47 doi:10.1 I86/147I-2458-8-47
Received: 23 July 2007

Accepted: 6 February 2008

This article is available from: http://www.biomedcentral.com/I47I-2458/8/47

(c) 2008 Puig et al; licensee BioMed Central Ltd.

This is an Open Access article distributed under the terms of the Creative Commons Attribution License (http://creativecommons.org/licenses/by/2.0), which permits unrestricted use, distribution, and reproduction in any medium, provided the original work is properly cited.

\begin{abstract}
Background: Awareness of the negative effects of smoking on children's health prompted a decrease in the self-reporting of parental tobacco use in periodic surveys from most industrialized countries. Our aim is to assess changes between ETS exposure at the end of pregnancy and at 4 years of age determined by the parents' self-report and measurement of cotinine in age related biological matrices.
\end{abstract}

Methods: The prospective birth cohort included 487 infants from Barcelona city (Spain). Mothers were asked about maternal and household smoking habit. Cord serum and children's urinary cotinine were analyzed in duplicate using a double antibody radioimmunoassay.

Results: At 4 years of age, the median urinary cotinine level in children increased 1.4 or 3.5 times when father or mother smoked, respectively. Cotinine levels in children's urine statistically differentiated children from smoking mothers (Geometric Mean (GM) $19.7 \mathrm{ng} / \mathrm{ml} ; 95 \% \mathrm{Cl}$ 16.83-23.0I) and exposed homes (GM 7.I ng/ml; 95\% Cl 5.6I-8.99) compared with non-exposed homes (GM $4.5 \mathrm{ng} / \mathrm{ml}$; 95\% Cl 3.7I-5.48). Maternal self-reported ETS exposure in homes declined in the four year span between the two time periods from $42.2 \%$ to $31.0 \%(p<0.01)$. Nevertheless, most of the children considered non-exposed by their mothers had detectable levels of cotinine above I $\mathrm{ng} / \mathrm{mL}$ in their urine.

Conclusion: We concluded that cotinine levels determined in cord blood and urine, respectively, were useful for categorizing the children exposed to smoking and showed that a certain increase in ETS exposure during the 4-year follow-up period occurred. 


\section{Background}

Involuntary exposure of preschool children to environmental tobacco smoke (ETS) in home where they spend most of their time is an important and preventable cause of morbidity. Evidence from meta-analyses and systematic reviews shows that ETS increases the risk for sudden infant death syndrome, middle ear disease, respiratory tract infections, and wheezing during childhood [1-3]. Furthermore, ETS exposure of young children has been associated with increase in carcinogen-protein adducts [4], which in turn may be considered as a potential risk of cancer later in life $[5,6]$.

In the last decades, awareness of the negative effects of smoking on maternal and fetal health and the benefits of quitting smoking prompted a decrease in the proportion of smoking mothers in most industrialized countries. Maternal self-reported smoking in periodic populationbased surveys revealed a decreasing trend or cessation of cigarette consumption during pregnancy [7-9] and during early life of their children $[10,11]$. In all these epidemiological studies, parental tobacco self-reporting has been the method of determining ETS exposure at home. According to the questionnaire, passive exposure from other sources beside home, such as bars, restaurants, etc. did not usually occur in children.

Although standardized questionnaires are widely used in indicating the smoking data at home, the frequency of underreporting is high, and the addition of an objective biological marker results in a more accurate estimate of ETS exposure in children [12].

Cotinine is a major metabolite of nicotine and is considered the best biomarker for nicotine exposure. Cotinine can be found in many biological matrices, such as blood, saliva, urine, meconium, and hair. Being a non-invasive test, the urinary cotinine measurement is among the most frequently used methods. Few cross-sectional studies have quantified ETS exposure in newborns [13] and children aged 4 to 16 years [14-17] using urinary cotinine levels. As far as we know, no longitudinal study has been conducted to assess ETS exposure in the same cohort at birth and at a preschool age by testing for urine cotinine.

Our aim wasto assess changes between ETS exposure at the end of pregnancy and at 4 years of age in a prospective birth cohort. We documented in this cohort that cord serum cotinine appeared to be the most adequate biomarker of fetal exposure to smoking at the end of the pregnancy [18]. In the same article (18), we reported a good correlation between cotinine concentrations in cord blood and neonatal urine. In the 4 year olds, the level of ETS exposure was determined by the parent's self-report and measurement of urinary cotinine, the most widely used biomarker for ETS in children.

\section{Methods}

\section{Study design and participants}

The included infants were gathered from the Barcelona cohort taking part in the Asthma Multicenter Infants Cohort Study (AMICS). The AMICS study is an ongoing multicenter observational study with the participation of different cohorts from Ashford (UK), Barcelona, Menorca (Spain), and Munich (Germany), the objective of which is to assess pre- and postnatal effects of different health and environmental factors on the inception of atopy and asthma. The Barcelona cohort included 487 infants from consecutive pregnant mothers attended at the antenatal visit in Hospital del Mar, Barcelona (Spain) between January 1996 and October 1998 who completed the questionnaire. Women were fully informed of the purpose of the study, the design of which included scheduled visits for both mothers and offsprings at fixed time points after delivery. Participants were invited to join the study if they anticipated living in the city during the forthcoming 6year study period and had a telephone number. The study protocol was approved by the institutional review board and mothers gave written informed consent.

\section{Demographic and neonatal characteristics}

At the first antenatal care visit to the hospital, usually during the third trimester of pregnancy, an exhaustive questionnaire was completed including maternal age, parental birth country and sociodemographic characteristics. Social class was defined by paternal occupation using the UK Registrar General's 1990 classification.

General information on delivery (gestational age, gender, weight and length and head circumference at birth) was recorded from medical records.

\section{Maternal self reported tobacco exposure characteristics}

Mothers were asked at both antenatal and the child's 4 year old visit about maternal, household smoking habit characteristics and the children's passive exposure from other sources beside home. Three categories of mothers were defined: non exposed-non smoker (NENS), exposednon smoker (ENS), smoker (S). If they were daily smokers, they were asked the average number of cigarettes currently smoked per day and the brand of cigarette. Regarding exposure to ETS, non-smoking and smoking mothers were asked if they were regularly exposed to ETS, where and by whom (husband or other people in the family and/or at work), the average number of cigarettes smoked per day, the average hours of exposure per day and the brand of cigarettes smoked by these people. 
Tobacco consumption by nicotine daily intake (NDI) and exposure to ETS by daily exposure to nicotine (DEN) were calculated as milligrams of nicotine NDI $=$ (mg nicotine/ cigarette) $*$ (number of smoked cigarettes/day); $\mathrm{DEN}=\sum_{\text {smokers }}\left[\mathrm{NDI}_{\text {smokers }} *\right.$ (hours spent with the smoker $/ 24$ hours $\left.)\right]$ $[19,20]$.

\section{Sample collection and chemical analysis}

Cord blood ( $\mathrm{n}=415,85.2 \%)$ was obtained at delivery, immediately centrifuged and the cord serum was collected. Children's urine samples $(n=306,62.8 \%)$ were collected at the age of 4 years. Urine samples were collected at a consistent time, in the morning, following the visit protocol. All samples were stored at $-80^{\circ} \mathrm{C}$ until analysis.

Cord serum and urinary cotinine were analyzed in duplicate using a double antibody radioimmunoassay according to a method described previously [21]. The limit of detection was $0.2 \mathrm{ng} / \mathrm{mL}$. We discontinued creatinine analysis in our study samples due to the low reliability of creatinine analysis in thawed samples as reported in our previous study [18] since creatinine precipitates as small crystals difficult to redissolve. Furthermore, other authors [22] found that creatinine-corrected urine cotinine concentrations showed less correlation with parental smoking history than did the uncorrected values.

Children exposed to ETS were stratified as non exposed (0-1 ng/ml), and low (1-14 ng/ml), medium (14-50 ng/ $\mathrm{ml})$, highly $(50-100 \mathrm{ng} / \mathrm{ml})$, and very highly (>100 ng/ $\mathrm{ml}$ ) exposed according to cord blood cotinine level groups used in a previous article [18]. In the absence of established cut-offs for urinary cotinine to differentiate levels of ETS exposure in childhood, it was decided to apply the same stratification criteria as used for cord blood. This choice was made considering that urinary cotinine in 4 years only reflects second-hand smoke (and thus only a passive smoking) while cord blood cotinine accounts not only for second hand smoke but also for maternal active smoke directly in contact with the fetus. Furthermore, this choice was supported by the fact that the half life of cotinine does not vary during childhood [23].

The subgroup of $246(50.5 \%)$ children with full data (questionnaire and both biomarkers:cord blood cotinine at birth and urine cotinine at the age of 4 years) was used to explore changes in the prevalence of ETS exposure between the two time points.

\section{Statistical analysis}

We compared sociodemographic and clinical data of mothers and their children using analysis of variance
(ANOVA) statistics for continuous variables and chisquare tests for categorical variables and Fisher's exact test in the case of small proportions.

To assess the relationship between maternal self-reported smoking habits and cotinine levels in children's urine at the age of 4 years, cotinine concentrations were log transformed to fit a normal distribution and Pearson coefficient (r) was calculated. Moreover, we used median and geometric means as average for evaluating a doseresponse relationship between self reported smoking habits (as the standard) and cotinine levels; groups of DEN in non-smoker mothers and groups of NDI in smoking mothers were stratified according to tertiles. Furthermore, to compare the four year old's urinary cotinine concentrations among children from NENS, ENS, and S, adjusting for potential confounders such as maternal age and sex of the child, a multiple linear regression analysis was conducted.

To assess the relationship between cotinine concentrations in the umbilical cord serum and the 4 year olds' urine samples, cotinine concentrations were log transformed to fit a normal distribution and gamma coefficient $(\gamma)$ correlation for ordinal variables was calculated.

Statistical significance was set at $\mathrm{p}<0.05$ and all analyses were performed using SPSS, version 11 (SPSS Inc, Chicago, Illinois, USA).

\section{Results}

Table 1 shows the characteristics of the study population at the two time periods of follow-up. Socio-economic status measured by paternal job had a broad distribution. The maternal ethnic distribution between Spanish (74.5\%) and non-Spanish (25.5\%) reflected the demography of population attending the Hospital del Mar. In the 4 year interval of follow-up, a significant percentage of non-Spanish mothers could not be contacted for various reasons (moved, telephone number changed, etc), but there were no statistically significant differences in neonatal environmental tobacco exposure between the retained group and the group which was lost in the 4 years span.

Indeed, in the group lost to follow up, the percentage of smoking mothers evaluated by biomarker was $29.5 \%$ and in the group retained for the follow up it was $33.6 \%$, p = 0.27 . The main cause of loss at follow up was the nonspanish origin of families (included in Table 1), but all the other characteristics are not different in the retained population compared to the original population, at birth. (sex $\mathrm{p}=0.25$, birth weight $\mathrm{p}=0.17$, length $\mathrm{p}=1$, low weight $\mathrm{p}$ $=0.62$, prematurity $\mathrm{p}=0.35$ ). 
Table I: Characteristics of the study population at delivery and at 4 years of age follow-up

\begin{tabular}{|c|c|c|c|}
\hline & At delivery $N=415$ & 4 year $N=306$ & p-value* \\
\hline \multicolumn{4}{|l|}{ Parents: } \\
\hline Maternal age at birth, mean (SD) & $29.1(5.4)$ & $29.8(5.3)$ & NS \\
\hline \multicolumn{4}{|l|}{ Father's social class, $(\%)$} \\
\hline Professional & 6.2 & 7.0 & NS \\
\hline Managerial and technical & 10.7 & 10.9 & NS \\
\hline Skilled (non-manual) & 40.9 & 38.5 & NS \\
\hline Skilled (manual) & 22.7 & 24.1 & NS \\
\hline Partly skilled & 16.9 & 16.0 & NS \\
\hline Unskilled & 2.6 & 3.5 & NS \\
\hline Maternal country, Spain (\%) & 74.5 & 81.0 & 0.01 \\
\hline \multicolumn{4}{|l|}{ Neonates: } \\
\hline Sex, male $(\%)$ & $5 I .1$ & 53.1 & NS \\
\hline Birth weight (g), mean (SD) & $3242.0(48 I .7)$ & $3180.4(492.5)$ & NS \\
\hline Length $(\mathrm{cm})$, mean $(\mathrm{SD})$ & $49.2(2.1)$ & $49.1(2.4)$ & NS \\
\hline Craneal perimeter $(\mathrm{cm})$, mean $(\mathrm{SD})$ & $34.4(1.5)$ & $34.2(1.6)$ & NS \\
\hline Low weight $(<2500 \mathrm{~g}),(\%)$ & 6.3 & 8.2 & NS \\
\hline Premature (<37 weeks), (\%) & 5.8 & 7.8 & NS \\
\hline
\end{tabular}

NS: no significance

Cotinine levels in the urine samples were not normally distributed, ranging from 0.20 to $300.90 \mathrm{ng} / \mathrm{mL}$, with the median at $9.60 \mathrm{ng} / \mathrm{mL}$, 25th percentile at $4.37 \mathrm{ng} / \mathrm{mL}$ and 75th percentile at $23.35 \mathrm{ng} / \mathrm{mL}$. Cotininelevels in cord blood are described in our previous publication [18].

When parent's smoking behavior was evaluated, urinary cotinine levels increased in parallel with the number of smokers in the household (Table 2).

There was a significant correlation $(\mathrm{r}=0.61, \mathrm{p}<0.001)$ between maternal smoking as expressed by NDI, and urinary cotinine levels in children, while maternal reporting of ETS exposure of their 4 year old offsprings, assessed as DEN, was slightly less correlated $(r=0.56, p<0.001)$ with the cotinine levels in the children's urine (Table 3).

Cotinine levels in children's urine from self-reported smoking mothers (Geometric Mean (GM) 19.7; 95\% Confidence Interval (95\% CI) 16.83-23.01) and exposed homes (GM 7.1; 95\% CI 5.61-8.99) were significantly higher than in children from non-exposed homes (GM 4.5 ; 95\% CI 3.71-5.48).

Maternal smoking habit according to the self-reports showed that the prevalence of active maternal smoking increased in the four year span (from $34.7 \%$ to $48.4 \%$, p $<0.001$ ) while ETS exposure in homes declined from $42.2 \%$ to $31.0 \%$ ( $<<0.01$ ) (Table 4$)$. In line with that evidence, the percentage of children not exposed to tobacco smoke decreased significantly, while a significant increase in the biomarker levels was registered only for low exposure to smoking.

Furthermore, to explore changes in the prevalence of ETS exposure, the subgroup of 246 children with both biomarkers:cord blood cotinine at birth and urine cotinine at the age of 4 years was categorized in the same groups of ETS exposure at the two time points $(\gamma=0.77)$ (Table 5). The prevalence decreased only at the extreme

Table 2: Reported parental smoking habit and cotinine levels in children's urine $(\mathrm{ng} / \mathrm{mL})$ at 4 years

\begin{tabular}{|c|c|c|c|c|c|}
\hline \multirow[t]{2}{*}{ Parental smoking status } & \multicolumn{5}{|c|}{ Urinary cotinine at 4 year $(\mathrm{ng} / \mathrm{mL})$} \\
\hline & $\mathbf{N}$ & Median & Mean (SD) & Range & p-value \\
\hline \multicolumn{6}{|l|}{ At 4 year: } \\
\hline No smoker & 94 & 4.60 & $6.50(6.68)$ & $0.20-36.00$ & - \\
\hline Only father & 64 & 6.45 & $10.57(11.23)$ & $1.10-57.40$ & 0.004 \\
\hline Only mother & 52 & 16.30 & $27.78(30.58)$ & $2.60-170.20$ & $<0.001$ \\
\hline Both mother and father & 96 & 19.60 & $33.06(41.47)$ & $2.10-300.90$ & $<0.001$ \\
\hline
\end{tabular}


Table 3: Cotinine levels $(\mathrm{ng} / \mathrm{mL})$ in children's urine and maternal self-reported smoking habit at 4 years

\begin{tabular}{|c|c|c|c|c|}
\hline \multirow[t]{2}{*}{ Maternal self-reported smoking habit at $\mathbf{4}$ years } & \multicolumn{4}{|c|}{ Urinary cotinine in children at 4 years $(\mathrm{ng} / \mathrm{mL})$} \\
\hline & $\mathbf{N}$ & Median & Adjusted GM & CI 95\% \\
\hline NENS & 102 & 4.65 & 4.53 & $(3.7 \mathrm{I}-5.48)$ \\
\hline ENS & 62 & 6.45 & $7.10^{*}$ & $(5.61-8.99)$ \\
\hline \multicolumn{5}{|l|}{ DEN child (Tertiles) } \\
\hline$\leq 2$ & $39(62.9 \%)$ & 5.40 & 6.38 & $(4.98-8.18)$ \\
\hline $2-4$ & $15(24.2 \%)$ & 6.50 & 7.23 & $(4.83-10.81)$ \\
\hline$>4$ & $8(12.9 \%)$ & 10.80 & 11.38 & $(6.55-19.77)$ \\
\hline $\mathbf{S}$ & 142 & 19.15 & $19.68^{*}$ & $(16.83-23.01)$ \\
\hline \multicolumn{5}{|l|}{ NDI mother (Tertiles) } \\
\hline$\leq 3.6$ & $15(10.6 \%)$ & 9.90 & 9.75 & $(6.14-15.49)$ \\
\hline $3.6-9$ & 48 (33.8\%) & 13.45 & 12.45 & $(9.59-16.14)$ \\
\hline$>9$ & 79 (55.6\%) & 28.50 & $30.4 I^{* * *}$ & $(24.89-37.24)$ \\
\hline
\end{tabular}

$* \mathrm{p}$-value $<0.05$ in relation to NENS

**** $\mathrm{p}$-value $<0.001$ in relation to the first tertile of maternal NDI

GM: geometric mean; Cl: confidence interval; NENS: non exposed-non smoker; ENS: exposed-non smoker; S: smoker; NDI:nicotine daily intake;

DEN: daily exposure to nicotine.

exposures (no exposure and very high exposure) and increased at medium exposure.

\section{Discussion}

Results of this study show that measurement of cotinine levels was useful not only for quantifying ETS exposure but also for categorizing the children exposed to smoking, and non-smoking mothers (categorized further in exposed to other smokers, and non-exposed). Furthermore, as a whole, a decrease in the percentage of non exposed children to tobacco smoke and an increase in the percentage of children with a small-medium ETS exposure have been documented during the 4-year follow-up period. Conversely, the very high exposure found at birth (measuring cotinine in cord blood) and coming from the direct feto-placental passage of high amount of tobacco smoke from heavy smoker mothers disappeared.
The moderate linear relationship between results of maternal self-reporting and urinary cotinine in the 4 year olds was useful to distinguish between the presence or absence of smoking mothers, in agreement with other studies $[15-17,24]$. On the basis of these results, different authors $[25,26]$ have suggested that the usefulness of selfreport questionnaires and urinary cotinine levels to assess ETS exposure was similar. However, in our study, in spite of the small numbers in some categories, we identified a total of $98.4 \%$ of our preschool population exposed to ETS, with about $8 \%$ children with urinary cotinine levels indicative of high and very high exposure to ETS.

According to the questionnaire, passive exposure from other sources beside home, such as bars, restaurants, etc. did not occur in these children (this was one of the questions in the data base of the study). Exposure from other household members or houses of relatives were not significant, according to the questionnaire as well; usually,

Table 4: Prevalence of environmental tobacco exposure: maternal report versus biomarker-based at birth and at 4 years of age

\begin{tabular}{|c|c|c|c|}
\hline & At delivery $N=415$ & 4th year $N=306$ & p-value* \\
\hline \multicolumn{4}{|l|}{ ETS exposure: } \\
\hline \multicolumn{4}{|l|}{ By questionnaire: } \\
\hline Active maternal smoking (NDI >0) (\%) & $144(34.7)$ & $148(48.4)$ & $<0.001$ \\
\hline Passive exposure(DEN >0) $(\%)$ & 175 (42.2) (mother DEN) & $95(3 \mid .0)$ (child DEN) & $<0.01$ \\
\hline By biomarker: & Umbilical cord blood & Child Urine & \\
\hline $0-\mathrm{I} \mathrm{ng} / \mathrm{mL}(\%)$ (no exposure) & $45(10.8)$ & $5(2.0)$ & $<0.001$ \\
\hline I - 14 ng/mL (\%) (low) & $228(55.0)$ & $186(60.4)$ & 0.02 \\
\hline$>14 \mathrm{ng} / \mathrm{mL}(\%)$ (medium and high) & $142(34.2)$ & $115(37.6)$ & 0.35 \\
\hline
\end{tabular}

ETS: environmental tobacco smoke; NDI: nicotine daily intake; DEN: daily exposure to nicotine 
Table 5: Biomarker based prevalence of tobacco exposure at birth and at 4 years $(N=246)$, according to the previously established intervals.

\begin{tabular}{lcc}
\hline Level of exposure $(\mathrm{ng} / \mathrm{mL})$ & Cord blood cotinine $\mathrm{n}(\%)$ & Urinary cotinine at 4 years $\mathrm{n}(\%)$ \\
\hline Non exposure $<1$ & $25(10.2)$ & $4(1.6)$ \\
Low exposure $1-14$ & $135(54.9)$ & $157(63.8)$ \\
Medium exposure $14-50$ & $23(9.3)$ & $66(26.8)$ \\
High exposure $50-100$ & $21(8.5)$ & $16(6.5)$ \\
Very high exposure $>100$ & $42(17.1)$ & $3(1.2)$
\end{tabular}

Chi-square $p<0.001$. Gamma Coef 0.770

these children spent their indoor time at home and school. In Spain, although smoking in some public places (eg. bars and some restaurants) is still permitted, the main source of environmental tobacco exposure for children is their home, usually because of parental smoking.

In the present study, the median urinary cotinine level in children living in households where the father smoked was 1.4 times higher and 3.5 times higher when mother smoked compared with children of non-smoking households. Our results are in good agreement with the results of several other studies reporting stronger effect of maternal smoking than paternal smoking on children's ETS exposure [15,27-30]. This maternal influence could be explained by the fact that children spend more time with their mothers at home. Therefore, if we consider that $98.4 \%$ of our study population is exposed to ETS and that this is mainly due to maternal smoking, we conclude that the percentage of children living in smoking households in our study is higher than the $38 \%$ of preschool children in the USA [31], 50\% in the UK [32] and 57\% in Northern European countries [33] and only similar to the $72.3 \%$ in Turkey [17]. It should be noted that maternal selfreported ETS exposure in homes declined from $42.2 \%$ at pregnancy to $31.0 \% 4$ years later. However, most of the children considered non-exposed by their mothers had detectable levels of cotinine above $1 \mathrm{ng} / \mathrm{mL}$ in their urine, indicating even more widespread ETS exposure than reflected by maternal self-reporting. It is unlikely that the finding of widespread ETS exposure resulted from deliberately underreported parental tobacco use. Christensen et al. [34] have suggested that the awareness of health risks from ETS exposure could be a bias for assessing objectively the ETS exposure. Therefore, the results of this study support the proposal that parental reports should not be completely trusted when evaluating ETS exposure among non-smoking parents and the use of biomarkers could be a more objective evaluation.

The detectable levels of urinary cotinine for most children reflect more accurately the amount of ETS exposure. Further research is needed to define better the degree of health risks associated with specific values of serum coti- nine. It is noteworthy, that in this study, in every matrix, cotinine concentrations are considerably higher than those reported by other authors $[13,16,26,29]$. Our results suggest that, these children are probably at even higher risk of developing asthma or other deleterious effects of tobacco exposure [35].

Moreover, even though community-level interventions, such as limiting of smoking in public places, may be able to reduce some sources of outdoor exposure, other interventions will be necessary to insure tobacco-smoke free households. Parental education is of paramount importance to avoid ETS exposure.

\section{Conclusion}

The results of this study support the proposal that parental reports should not be completely trusted when evaluating ETS exposure among non-smoking parents and the use of biomarkers could be a more objective evaluation.

Cotinine levels determined in cord blood and urine, respectively, were useful for categorizing the children exposed to smoking and reflected the changes in the degree of exposure at the two time periods. Our results indicate that maternal smoking makes a significant contribution to children's ETS exposure. To our knowledge no other studies have measured ETS exposure in the same pediatric population at two different periods, at birth and at 4 years of age. Children should be more protected from ETS at home. Parents must be strongly advised to quit smoking around their children.

\section{Competing interests}

The author(s) declare that they have no competing interests.

\section{Authors' contributions}

OGA and CP had primary responsibility for study design, protocol development, patient screening, enrollment, outcome assessement, and writing the manuscript.

CF contributed primarily to patient enrollment, and acquisition of data. 
JS, PZ and RP, participated in the development of the protocol, and discussion of results.

TM executed statistical analysis of data and participated in results discussion.

SP supervised the design and execution of the study, performed the final data analyses, and contributed to the writing and revising of the manuscript.

OV participated in the design and the coordination of the study, and helped to draft the manuscript.

All the authors read and approved the final manuscript.

\section{Acknowledgements}

The Asthma Multicenter Infants Cohort Study received the following funding: FIS 95/0314, FIS 96/0799, FIS 00/002I, FIS 03/0296, Istituto Superiore di Sanitá, CIRIRT-I999SGR 0024I, COLT Foundation.

The authors thank Julia Klein for her help and critical comments with the editing of the manuscript.

\section{References}

I. Anderson HR, Cook DG: Passive smoking and sudden infant death syndrome: review of the epidemiological evidence. Thorax 1997, 52:1003-9.

2. Cook DG, Strachan DP: Summary of effects of parental smoking on the respiratory health of children and implications for research. Thorax 1999, 54:357-65.

3. DiFranza JR, Aligne CA, Weitzman M: Prenatal and postnatal environmental tobacco smoke exposure and children's health. Pediatrics 2004, I I 3:1007- I5.

4. Tang D, Warburton D, Tannenbaum SR, Skipper P, Santella RM, Cereijido GS, Crawford FG, Perera FP: Molecular and genetic damage from environmental tobacco smoke in young children. Cancer Epidemiol Biomarkers Prev 1999, 8:427-3I.

5. Bartsch J, Hictanen E: The role of individual susceptibility in cancer burden related to environmental exposure. Environ Health Perspect 1996, I04(Suppl 3):569-77.

6. Perera FP: Environment and cancer: who are susceptible? Science 1997, 278:1068-73.

7. Stewart PJ, Potter J, Dulberg C, Niday P, Nimrod C, Tawagi G: Change in smoking prevalence among pregnant women 1 982-93. Can J Public Health 1995, 86:37-4I.

8. Eriksson KM, Haug K, Salvesen KA, Nesheim BI, Nylander G, Rasmussen S, Andersen K, Nakling JO, Eik-Nes SH: Smoking habits among pregnant women in Norway 1994-95. Acta Obstet Gynecol Scand 1998, 77:159-64.

9. Hakansson A, Lendhals L, Petersson C: Which women stop smoking? A population-based study of $\mathbf{4 0 3}$ pregnant smokers. Acta Obstet Gynecol Scand 1999, 78:217-24.

10. Soliman S, Pollack HA, Warner KE: Decrease in the prevalence of environmental tobacco smoke exposure in the home during the 1990s in families with children. Am J Public Health 2004, 94:314-20

II. Lund KE, Helgason AR: Environmental tobacco smoke in Norwegian homes, 1995 and $200 \mathrm{I}$ : changes in children's exposure and parents attitudes and health risk awareness. Eur J Public Health 2005, I:I23-7.

12. Benowitz NL: Cotinine as a biomarker of environmental tobacco smoke exposure. Epidemiol Rev 1996, I 8: I88-204.

13. Nafstad P, Kongerud J, Botten G, Urdal P, Silsand T, Pedersen BS, Jaakkola J]: Fetal exposure to tobacco smoke products: a comparison between self-reported maternal smoking and concentrations of cotinine and thiocyanite in cord serum. Acta Obstet Gynecol Scand 1996, 75:902-907.
14. Mannino DM, Caraballo R, Benowitz N, Repace J: Predictors of cotinine levels in US children. Chest 200I, I 20:718-24.

I5. Thaqi A, Franke K, Merkel G, Wichmann HE, Heinrich J: Biomarkers of exposure to passive smoking of school children: frequency and determinants. Indoor Air 2005, I 5:302-3 I0.

16. Vardavas $\mathrm{Cl}$, Tzatzarakis MN, Tsatsakis AM, Athanasopoulos D, Balomenaki E, Linardakis MK, Kafatos AG: Biomarkers of passive smoking among Greek preschool children. Eur J Pediatr 2006, 165:89|-6.

17. Boyaci H, Etiler N, Duman C, Basyigit I, Pala A: Environmental tobacco smoke exposure in school children: parent report and urine cotinine measures. Pediatr Int 2006, 48:382-9.

18. Pichini S, Basagana XB, Pacifici R, Garcia O, Puig C, Vall O, Harris J, Zuccaro P, Segura J, Sunyer J: Cord serum cotinine as a biomarker of fetal exposure to cigarette smoke at the end of pregnancy. Environ Health Perspect 2000, 108:1079-83.

19. Rosa M, Pacifici R, Altieri I, Pichini S, Ottaviani G, Zuccaro P: How the steady-state cotinine concentration in cigarette smokers is directly related to nicotine intake. Clin Pharmacol Ther 1992, 52(3):324-329.

20. Segura J, Pichini S, Roig R, Ortuño J, García O, Sunyer J, González M, Puig C: Análisis en pelo de nicotina y cotinina para valorar el consumo y la exposición ambiental al tabaco durante el embarazo: un estudio piloto. Rev Esp Toxicol 2000, I 7:27-32.

21. Van Vunakis H, Gijka HB, Langone J): Radioimmunoassay for nicotine and cotinine. IARC Sci Publ 1993, 109:293-9.

22. Jatlow P, McKee S, O'Malley SS: Correction of urine cotinine concentrations for creatinine excretion: is it useful? Clin Chem 2003, 49:1932-4.

23. Leong JW, Dore ND, Shelley K, Holt EJ, Laing IA, Palmer LJ, LeSouef PN: The elimination half-life of urinary cotinine in children of tobacco-smoking mothers. Pulm Pharmacol Ther 1998, I I :287-90.

24. Ino T, Shibuya T, Saito K, Ohshima J, Okada R: A passive smoking screening program for children. Prev Med 2006, 42:427-9.

25. Bakoula CG, Kafritsa YJ, Kavadias GD, Lazopoulou DD, Theodoridou MC, Maravelias KP, Matsaniotis NS: Objective passive-smoking indicators and respiratory morbidity in young children. Lancet 1995, 346:280-I.

26. Rylander E, Pershagen G, Eriksson M, Bermann G: Parental smoking, urinary cotinine, and wheezing bronchitis in children. Epidemiology 1995, 6:289-93.

27. Scherer G, Kramer U, Meger-Kossien I, Riedel K, Heller WD, Link E, Gostomzyk JG, Ring J, Behrendt H: Determinants of children's exposure to environmental tobacco smoke (ETS): a study in Southern Germany. J Expo Anal Environ Epidemiol 2004, 14:284-92.

28. Pirkle JL, Flegal KM, Bernert JT, Brody DJ, Etzel RA, Maurer KR: Exposure of the US population to environmental tobacco smoke: the Third National Health and Nutrition Examination Survey, I998 to I99 I. JAMA 1996, 275: I233-40.

29. Henschen M, Frischer T, Pracht T, Spiekerkötter E, Karmaus W, Meinert R, Lehnert W, Wehrle E, Kuehr J: The internal dose of passive smoking at home depends on the size of the dwelling. Environ Res 1997, 72:65-7I.

30. Wong GC, Berman BA, Hoang T, Bernaards C, Jones C, Bernert JT: Children's exposure to environmental tobacco smoke in the home: comparison of urine cotinine and parental reports. Arch Environ Health 2002, 57:584-90.

31. Gergen PJ, Fowler JA, Maurer KR, Davis WW, Overpeck MD: The burden of environmental tobacco smoke exposure on the respiratory health of children 2 months through 5 years of age in the United States: Third National Health and Nutrition Examination Survey, 1988 to 1994. Pediatrics I998, I0 I:E8.

32. Jarvis MJ, Goddard E, Higgins V, Feyerabend C, Bryant A, Cook DG: Children's exposure to passive smoking in England since the I 980s: cotinine evidence from population surveys. BMJ 2000, 32 I:343-5.

33. Lund KE, Skrondal A, Vertio H, Helgason AR: To what extent do parents strive to protect their children from environmental tobacco smoke in the Nordic countries? A population-based study. Tob Control 1998, 7:56-60.

34. Chirstensen AE, Tobiassen M, Jensen TK, Wielandt H, Bakketeig L, Høst A: Repeated validation of parentalself-reported smoking during pregnancy and infancy: a prospective cohort study of infants at high risk for allergy development. Pediatr Perinat Epidemiol 2004, I8:73-9. 
35. Vork KL, Broadwin RL, Blaisdell RJ: Developing asthma in childhood from exposure to secondhand tobacco smoke:insights from a meta-regression. Environ Health Perspect 2007, I I 5: $1394-400$

\section{Pre-publication history}

The pre-publication history for this paper can be accessed here:

http://www.biomedcentral.com/1471-2458/8/47/prepub

Publish with Bio Med Central and every scientist can read your work free of charge

"BioMed Central will be the most significant development for disseminating the results of biomedical research in our lifetime. " Sir Paul Nurse, Cancer Research UK

Your research papers will be:

- available free of charge to the entire biomedical community

- peer reviewed and published immediately upon acceptance

- cited in PubMed and archived on PubMed Central

- yours - you keep the copyright 